DEarEST co-creation paper Health and Social Care in the Community

\title{
Healthy ageing in a deprived northern UK city: a co-creation study
}

\section{Abstract}

With ageing comes an increased risk of poor health and social isolation, particularly in poorer populations. Older people are under-represented in research and as a result interventions may not take account of their context or barriers to participation. In co-creative work future service users work with professionals on an equal basis to design, develop and produce a service or intervention. Our objectives were to i) undertake a co-creation study with older people living in a northern city in the United Kingdom, ii) explore maintenance of health and wellbeing in older age, iii) explore the application of co-creation with an older community population and iv) evaluate the process and inform future work. The study was conducted during 2016 by a project team of ten lay community dwelling older people and four university researchers. Findings demonstrate that state of mind and of health were key to wellbeing in older age. Feeling safe, comfortable and pain free were important along with being able to adapt to change, have choice and a sense of personal freedom. Social connectedness was seen as the keystone to supporting healthy behaviours. Rather than developing new interventions, there was a perceived need to connect people with existing resources and provide a human "bridge" to address barriers to accessing these. In conclusion, the co-creation process proved productive, even when undertaken on a small scale. The scope of the project needs to be realistic, to use diverse methods of recruitment and skilled facilitators, and to prepare well in terms of accessibility, simple systems and appropriate information provision.

Key words - Co-creation, older people, healthy ageing, wellbeing, loneliness, social isolation 
DEarEST co-creation paper Health and Social Care in the Community

\section{What is known about the topic:}

- There is a need to support healthy ageing in a population with a growing number of older people.

- Older people tend not to be included in developing services.

- Co-creation is an approach which supports the development of innovative and effective interventions and services.

\section{What this paper adds:}

- The conceptualisation of social connectedness keystone of healthy ageing which can be addressed by employing existing local services supported by a human 'bridge' to match individual need and existing resources.

- An understanding of the importance of identifying locally specific challenges and resources, and working with these.

- An example of, and insight into, a co-creation project with an accompanying process evaluation and critique of the project. 
DEarEST co-creation paper Health and Social Care in the Community

\section{Healthy ageing in a deprived northern UK city: a co-creation study}

\section{INTRODUCTION}

The population is ageing and with age comes an increased risk of poor health and prevalence of long-term conditions (Banerjee, 2015; Steptoe, Deaton \& Stone, 2015). This is particularly evident in poorer and deprived populations (Beard \& Bloom, 2015; Högberg, Strandh, Baranowska-Rataj \& Sevä, 2017; Olofsson, Padyab \& Malmberg, 2018). Social isolation is increasingly common amongst older citizens and can have a negative impact on physical health and emotional wellbeing (HoltLunstad, Smith, \& Layton, 2010; Newall \& Menec, 2015; Shankar, McMunn, Banks \& Steptoe 2011; Taylor, Taylor, Nguyen, \& Chatters 2018). Globally health and social care organisations are prioritising healthy ageing. The World Health Organisation (WHO) (WHO 2020) advocates for every person having the opportunity to live a long and healthy life. International and national policies and initiatives support empowerment of citizens to live healthy and active lives and the development of sustainable and efficient health systems (UK Research and Innovation 2020).

Health promotion is an essential element of supporting healthy ageing. The wealth of information on staying healthy in older age, for example, prevention of stroke, heart disease, cancer and dementia suggests that overall five key elements significantly contribute to health and wellbeing. These include adequate hydration (e.g. Picetti, et al. 2017), healthy diet (e.g. Jankovic, et al. 2014), exercise (e.g. Taylor, 2014), rest (Gulia \& Kumar, 2018) and social interaction (e.g. DomènechAbella, et al. 2017). Increasingly efforts are directed at promoting wellbeing in older age (Grönvall \& Kyng, 2013; Lood, Häggblom-Kronlöf \& Dahlin-Ivanoff 2015; Suzman, Beard, Boerma \& Chatterji 2015). Recent reviews of health promotion activities specifically targeting older people attest to the growing body of work in this field. For example there are systematic reviews addressing physical activity (Oliveira, Sherrington, Amorim, Dario \& Tiedemann 2017), diet (Patnode, Evans, Senger, 
DEarEST co-creation paper Health and Social Care in the Community

Redmond \& Lin 2017) and interventions to address social isolation and loneliness (Gardiner, Geldenhuys \& Gott 2018). Other reviews consider more targetted groups such as people at risk of, or living with, early stage frailty (Frost, et al. 2017; Gardner, et al. 2017), falls (Cameron, et al 2012) and 'hard to reach' groups (Liljas, et al. 2017). Despite the growing focus of health promotion toward older people, recommendations are often couched in complex health care language, which can alienate people. In everyday language, the general messages are; good hydration (D्ink),

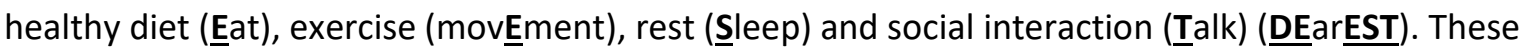
elements provided the starting point for discussions around wellbeing in this co-creation project.

When designing interventions (strategies) to support such health behaviours the literature recommends that to be effective they are i) tailored (Baker, et al. 2015) according to ii) theoretically assessed behavioural determinants (barriers and facilitators) (Michie, et al. 2005) and iii) underpinned by behaviour change techniques (Craig, et al. 2008). One approach is the Theoretical Domains Framework (TDF) (Michie, et al. 2005) which comprises 11 domains (knowledge, skills, social role and identity, beliefs about capabilities, beliefs about consequences, motivation and goals, memory attention and decision processes, environmental context and resources, social influences, emotion, action planning). This approach has been implemented successfully to support health behaviour change including, for example, diet (McEachan, et al. 2016; Taylor, et al. 2013), exercise (Munir, et al. 2018), and for these reasons was selected to underpin this study.

Co-methodologies are increasingly prominent in health care research, the value being, they bring together researchers and service users to facilitate innovation and improved performance (Jackson \& Greenhalgh, 2015). The particular relevance of using co-methods in our study is that it privileges social equality, dignity and wellbeing across all participants (Jansen and Pieters, 2017). These factors often get overlooked in a world where research is more likely to be done 'to', 'about' or 'for', rather than 'with' or 'by' older people (Schilling \& Gerhardus, 2017). 
DEarEST co-creation paper Health and Social Care in the Community

The language of co-working remains a disputed concept without absolute definition and the terms co-creation, co-design, co-production and participatory working are used interchangeably. Current policy emphasises the need for pragmatic, 'real world' research in which local contexts are addressed to ensure successful implementation of complex interventions (Jackson \& Greenhalgh, 2015). Effective co-working requires lay people and professionals to work as equals at every stage in the research process (Co:Create, 2020; National Institute for Health Research (NIHR) INVOLVE, 2020) poorly executed co-working risks tokenism (Jackson \& Greenhalgh, 2015). Achieving effective and meaningful co-working is extensively considered in the literature (Filipe, Renedo, \& Marston, 2017). Good practice guidance suggests the core elements of meaningful co-working include early engagement of stakeholders, respecting the views of all participants, conscious management of power relations and inter-personal interactions (Flinders, Wood \& Cunningham, 2016; NIHR INVOLVE, 2020; Shimmin, Wittmeier, Lavoie, Wicklund \& Sibley, 2017). Older people are underrepresented in research and are at risk of systematic exclusion (Shimmin, et al. 2017). While partnerships are becoming more common, co-methodological working has been slower to develop with this group than with others (Blair \& Minkler, 2009; Littlechild, Tanner \& Hall, 2015). This is problematic, as the lack of inclusion of older adults may result in interventions which do not account for their context or barriers to their participation. Services or interventions are then less effective due to this poor match. Having considered available literature for co-creative working with older people, for the purpose of this paper we have conceptualised co-creation based on the core values of 'Co:Create' (Co:Create, 2020) which embrace an approach that is holistic, resourced, transparent, inclusive, iterative, positive, equal and sustainable.

This paper firstly provides a description of a theoretically informed co-creation study to investigate what it means to maintain health and wellbeing in older age and how to support this in a local context. Secondly, we offer process evaluation with reflections and recommendations on practice and effective co-working. Objectives were to: i) develop a shared understanding of the meaning of 
DEarEST co-creation paper Health and Social Care in the Community

healthy ageing, ii) identify barriers and facilitators to adopting behaviours that would support the identified essential components of healthy ageing, iii) make recommendations for adapting local services or developing new ones that are feasible, acceptable and sustainable and iv) evaluate and make recommendations for authentic co-creation with older people.

\section{METHODS}

An iterative co-creation approach was taken using a qualitative approach (Stebbins, 2001) underpinned by the Theoretical Domains Framework (Michie, et al. 2005) and the core values of 'Co:Create' (Co:Create, 2020).

\section{Setting and participants}

A northern UK city, ranking in the top 10 of the UKs most deprived local authorities in terms of factors such as income, employment, health and disability, education, housing and living environment (Ministry of Housing, Communities and Local Government, 2019). Our study site was selected as the local Clinical Commissioning Group (CCG) (Health Service organisation responsible for planning and commissioning local health service) recognised the need to support healthy ageing in this locality. All meetings were held in a central and easily accessible venue.

We recruited lay members through posters, attendance at community groups, via social media and by the University members presenting on a local radio station. Interested individuals contacted one of the university members who provided further information and answered questions. Our aim was a maximum variation sample (Palinkas, et al. 2015).

The co-creation group comprised 
DEarEST co-creation paper Health and Social Care in the Community

- Ten lay people aged between 70 and 79 years; seven were women and three men. All were white British, four were married, three identified as having a disability, four had no formal education, one left school at 16, and five had engaged in higher education. Lay members had time and travel expenses reimbursed.

- Four university members were all female research academics aged from 27-57 and White British. All had doctoral level education and they had had expertise in psychology, nursing, behaviour change, co-methodological working and qualitative research methods.

\section{Data collection}

Data were collected through audio recordings of the project group meetings, field notes recorded by one of the research team, email and telephone exchanges with group members between meetings, and feedback questionnaires completed after the final group meeting.

The group met on four occasions for two-hour project meetings between August and October 2017. Attendance is summarised in Table 1.

Insert Table 1 here.

Introductions were made and ground rules agreed at the first meeting. Each meeting had a focus and an open structure to allow the group to direct discussion. Group members had diverse backgrounds, life experiences and they boldly expressed their views. These were either i) debated until agreements were made or ii) a range of views were accepted according to personal contexts. This process was at times uncomfortable but led to greater group cohesion, better understanding and potentially more robust outcomes from the study. Meetings were audio recorded and field notes taken. Lay members collected agreed information (e.g. available local resources). The theme 
DEarEST co-creation paper Health and Social Care in the Community

of the first meeting was set by the university team, subsequent themes developed organically out of the group discussion. The university team met between meetings to review the content of the previous meeting and consider the theme which most clearly emerged from that discussion in order to provide a starting point for the next meeting. These were then suggested to the group. The themes of the four meetings were:

1. What is the "key" to healthy ageing?

2. What helps and hinders achieving healthy ageing?

3. What local resources already exist? What needs to be changed? What additional resources are needed?

4. What are our recommendations to address healthy ageing and what are our experiences of the co-creation process?

A questionnaire, comprising five open questions, was distributed to all team members after the final group meeting. This was in part to further gauge thoughts about the project. In addition, as part of the process evaluation, team members were asked about their experiences of the co-creation process and suggestions for changes. Team members could email or post their responses. Pre-paid envelopes were provided. Items in the questionnaire were as follows:

1. What was your experience of being part of the project?

2. What do you think are the key things we have discussed?

3. Was there anything that stood out to you?

4. What do you think should happen next?

5. What you would suggest doing differently if we run a project like this in the future?

\section{Data analysis}

Outcome data: Data collection and analysis were iterative. Audio recordings, emails and telephone calls, field note data and evaluation questionnaires were thematically analysed in order to address 
DEarEST co-creation paper Health and Social Care in the Community

the four objectives identified in the introduction section of this paper. Between meetings, university members reviewed notes and listened to audio recordings. From these they summarised and processed discussions which were presented to, and reviewed by, the whole team to ensure a full and accurate representation of conversations and provide a starting point for the next meeting discussion. As this was a co-creation project, it was not possible to know the direction the discussions would take during the course of the meetings. Further analysis was undertaken after the completion of the project to ensure authenticity of the themes generated and to ensure they focused on the specific objectives of the project. Our aim was to identify descriptive themes which summarised the key points discussed in relation to the research objectives. At this point meeting recordings and study of all written material was included. Data immersion was achieved through repeated listening to meeting recordings; initial codes were generated, and themes addressing each objective were derived, defined and named. Within the area of each objective, themes were derived inductively and are descriptive at a semantic level. The analysis process was informed by the principles of thematic analysis Ryan \& Bernard (2003). Decisions on final themes were discussed amongst members of the university team. Subsequently the university members mapped the barriers and facilitators of DEarEST elements identified by the group to the TDF.

Process data: A process evaluation was undertaken through the group reflections on the co-creation experience. Group reflections were considered in relation to the core values of 'Co:Create' (Co:Create, 2020) to assess the extent to which these standards for improvement in subsequent projects. Initial data analysis was completed by the university members and circulated to the rest of the group for review and amendment. 
DEarEST co-creation paper Health and Social Care in the Community

\section{Ethical considerations}

Ethical approval was given by the School of Health and Social Work at the University of Hull (ref:

266). All participants were given an information sheet outlining the project and what was required, written consent was obtained from all lay members of the group.

\section{FINDINGS}

Results are discussed below according to each of the specified objectives. The DEarEST elements offered a starting point for discussion. The findings include illustrative quotes, the majority of which are taken from meeting recordings. There are additional quotes from the final questionnaires and personal communications. As we were working as an equal team, we have not identified whether quotes come from lay or university participants. All meeting and personal communication quotes except one, come from lay members. An equal number of quotes from the final questionnaire come from lay and university participants. We have ensured that quotes come from a range of participants.

\section{Develop a shared understanding of the meaning of healthy ageing}

The group sought to define "older" and "elderly". Initial discussions focused on the ideas of dependency and lack of control but further exploration within the group revealed these to be stereotypes rather than reflecting the realities experienced by team members. We talked about the physical components of DEarEST, however these were not perceived as key by the team who concluded that being able to adapt to change, having choice and a sense of personal freedom were important. "When your family's grown up and you got your own time, that's when it's your time that's when you can feel this is good.... you can do your own thing". Then we considered the disconnect between physical changes which come with age and a continuing sense of self; "my body is old but I don't think any differently than I did at 22". We spoke about idea that life as an older 
DEarEST co-creation paper Health and Social Care in the Community

person is a continuation of life in general; "whatever happens in your life, the next step is a new chapter. When you retire that's a new chapter". Overall, the team concluded a positive attitude and feeling "safe, secure and pain free" are essential to healthy ageing.

We decided in the group that the "key" to maintaining health was to address loneliness, being alone and a lack of connections. The group suggested that these were factors which lead to people feeling vulnerable. "Loneliness is the killer", however, connecting people was not always seen to be easy "how do you get people out there?" while "offering a choice". Having social interactions increased the likelihood of engagement in other DEarEST elements, as either a direct or indirect result of reduced loneliness. The team considered that individuals who were socially engaged might be more motivated to self-care and that eating, drinking and movement might well take place in a social context. All of these could in turn aid sleep. "It was interesting how we had the different dearest elements, but it was loneliness/social isolation that people felt was the most important issue, both in terms of an issue in itself and as something that underpins everything else" (final questionnaire). However loneliness itself was seen as a barrier to engagement; "If you haven't got a hand to hold..... that is a block even to get out of the door".

Identify barriers and facilitators to adopting behaviours that would support the identified essential components of healthy ageing

Memory and making decisions were discussed, the reality of being older is that people often have fewer resources of all kinds, some people need more thinking time as they get older and need things to be slower. Presenting options to support decision-making may help develop connections; "mechanism that identifies ... and then puts them in touch with [list of organisations] ... and gets message across." Whilst important such resources alone are not sufficient. Knowledge about existing resources was problematic. Those without computer skills or access to the internet were 
DEarEST co-creation paper Health and Social Care in the Community

less likely to know about the many existing groups and opportunities. "The thing which stood out for us was the vast amount of material in hard copy and online available from local and national authorities and charities both large and small. The disappointment is that the majority of it does not reach its target audience. This became clear in our group by the amount of previously unknown information being tabled" (final questionnaire). Lack of confidence and belief in their abilities stops some people from going to new activities. We talked about there being "something about stepping over the threshold" and "having inspiration, seeing people like you doing the thing". Practical constraints including poverty can exacerbate isolation "if you don't have the wherewithal, then you've got restricted resources so you don't go out". Environmental barriers included lack of affordable and convenient transport and easy access to toilets, "the thought of having to go out, change a bus, maybe find a public toilet ...is very debilitating"

\section{Make recommendations for adapting local services or developing new ones that are feasible, acceptable and sustainable}

The recommendations made were based on the premise derived from group discussion that social connection is the keystone which, if present, supports the other DEarEST behaviours (good hydration, healthy diet, exercise, rest) and protects against health risks of loneliness. Indirect support of DEarEST behaviours is likely to be more powerful than direct targeting of the individual behaviours. There is no lack of opportunities and activities for older people in this city. Lack of engagement relates to barriers cited above. The group concluded that a person acting as a "bridge" between older people and activities was likely to be the most effective way to support people to access what is available, "human contact makes it more manageable and more real". We did not consider that making information available and signposting was enough, rather letting people know "there are things available ...we could contact them and you might get somebody who would take you or welcome you if you got there, that sort of thing" "Talking, talking to a person" was central to 
DEarEST co-creation paper Health and Social Care in the Community

the idea; that person could be a volunteer. As highlighted by the lay participants, the locality has access to an extraordinary resource in an established local volunteering network - a group who started as part of a City of Culture and who have continued to be involved in local projects. They are well trained and skilled in working with people.

From the data presented above, implementing the DEarEST findings requires the following steps each of which links to identified TDF barriers:

1. Create self-governing, community led group including older people, interested others from the community and local stakeholders.

2. Identify people who are, or who are at risk of being, isolated using formal and informal community networks (e.g. local shops, health centres and media).

3. Create a comprehensive list of activities, services, opportunities open to, or specifically for, older people across the locality (information) and make it accessible to all.

4. Work with individuals to find ways of making connections using the full range of opportunities including internet, individual or group events (encouragement and support).

5. Work with the established local volunteering network to act as "bridge" between older people and available resources. The bridge function might involve accompanying them, helping with preparation or practicalities such as how to get there, what, if anything, is needed. Volunteers would later withdraw and allow the person to continue in their new activity (encouragement, support, persuasive communication and prompts, contextual changes)

6. Older people who have benefitted from the project may be recruited to build a sustainable locality based network. 
DEarEST co-creation paper Health and Social Care in the Community

\section{Evaluate and make recommendations for co-creation with older people}

We evaluated the process against the core values of 'Co:Create' (Co:Create, 2020).

1. "Holistic: Coproduction should happen at every stage". As with many funded research studies the broad question and preliminary methods were necessarily decided before recruitment to the group. Other than the planning stage, co-creation took place at every stage of the project from design to dissemination. As a result of this, we are a group of people determined to publicise and progress ideas and we have established goodwill and links with statutory and voluntary organisations through existing networks and those resulting from the project.

2. "Resource: Meaningful and effective coproduction deserves and requires sufficient resource". The funding budget included payment for all members of the co-creation group and the provision of a private meeting room in an accessible and comfortable venue with refreshments.

3. "Transparent; Coproduction should have a clear and transparent remit, i.e.: overall aims, limitations, expectations and commitment". The group shared written and verbal information about the aims of the project and agreed both ground rules and levels of involvement. Although a broad research question had already been defined, the group shaped how this might best be addressed.

4. "Inclusive: coproduction should involve a wide range of people, capturing individual and differing views". Our recruitment strategy was broad and we were successful in ensuring diversity in age, gender and education. There was a lack of ethnic mix which is typical of the local, older population. Group discussion revealed diversity in life experiences and loyalty to micro-local cultural norms. However, one participant left the group after one session as they felt the group was not representative of the older people of the locality. 
DEarEST co-creation paper Health and Social Care in the Community

5. "Iterative: coproduction should be reciprocal, repeated and progressive, always adapting and building on what came before". As discussed above, verbal and written information, circulated through feedback loops, encouraged all members to challenge and contribute.

6. "Positive; coproduction should be mutually beneficial and an overall positive experience". Good humour dominated all interactions. Members enjoyed taking part, for example feeling "quite privileged to be part of the project" (email). On rare occasions group members noticed that others might not be contributing and this was addressed by offering opportunities and support for individuals to take a more active part in meetings if they desired.

7. "Equal: each participant and their contribution should be valued equally". For practical reasons, the project was facilitated and administered by academic group members, this arguably challenges equality. In order to mitigate this challenge, we used light touch facilitation, allowing the discussion to take its own direction and intervening to summarise or highlight issues of time. We derived our theme suggestions for group meetings in the discussion from the previous meeting. We reflected as a team between meetings on our input and the issue of equality.

8. "Sustainable: Meaningful coproduction should have a genuine sustainable impact on the project". As a result of the project we are a small cohesive team who intend to take forward the findings of this project to develop a locally sustainable models of connectedness. "I would like to see our team presenting to a CCG group" (final questionnaire), "a really huge media storm.." (final questionnaire), "raising awareness in local communities could be a good place to start" (final questionnaire). .

This evaluation suggests that in areas we were faithful to the process but that we did not achieve the core values in every respect. Collectively the group offer four recommendations for effective cocreation. Firstly, prepare well. Choose an accessible, familiar community location to make it easy for people to attend. Put in place simple payment systems and offer sufficient information to all 
DEarEST co-creation paper Health and Social Care in the Community

team members in preparation for the meetings. Secondly, be realistic about the scope of the project. This project was ambitious and we could not address everything at once, however there was some optimism that it would be possible to make a difference: "Trying to solve all the problems at once is like eating an elephant, eat it all at once and it will kill you, a little at a time and it's doable. Perhaps targeting one aspect may be the way forward" (final questionnaire). Thirdly, use diverse methods of recruitment to ensure representation from all potential stakeholders and to avoid the likelihood of "Preaching to the converted" (telephone call), i.e. having a team who are not fully representative of all older people in the city, who are socially engaged and confident enough to take part, and may have similar views to each other. Finally, use skilled facilitators. Although an agenda was prepared for each meeting the whole team steered the discussion. "At first I was worried that the conversation might go around in circles and get nowhere. But, every week I was surprised by how much progress we made. How, despite the diversity of the group we agreed isolation/ loneliness/connectedness were so important to health" (final questionnaire). There was a value in the university members collating and summarising information from each meeting to feed back at the beginning of subsequent meetings. "Often during the group I would not realise just how much richness there was in the discussion" (final questionnaire).

\section{DISCUSSION}

This study was based on the premise that known factors which influence healthy ageing, namely good hydration, healthy diet, exercise, rest and social interaction would be the focus of our cocreation group. However, older group members identified that feeling safe, comfortable and pain free were far more important elements of healthy ageing along with being able to adapt to change, have choice and a sense of personal freedom. Social connectedness was seen as the keystone to supporting other healthy behaviours for which numerous programmes and activities already existed in the locality. The conception of social connectedness held by our older group members varied from that presented in the extant literature. They envisaged themselves, and likeminded peers, taking an 
DEarEST co-creation paper Health and Social Care in the Community

active and leading role in being the "social connectors" in their local community and thus implicitly understanding the local community and culture (Bruggencate, Luijkx \& Sturm, 2018). In contrast, others describe a "done to" approach with interventions delivered by carers in differing guises (O’Rourke, Collins \& Sidani, 2018; Morgan, et al. 2019). Rather than developing new interventions, the group perceived a need to connect people with existing resources and provide a human "bridge" to address barriers to accessing these. Our work has starkly highlighted the need to co-create with older people to ensure that interventions meet their needs using approaches that are likely to succeed (Botero \& Hyysalo, 2013; Leong \& Johnston, 2016). The focus on social connectedness as a keystone is in line with the idea of connection being a fundamental human need which is critical to health and wellness (Martino, Pegg \& Frates, 2015).

There are numerous examples of co-creation with older people, however few published studies have addressed health promotion issues. Those that have often lack clarity in specifying the aim of including older people's participation, ways in which the input from older people was facilitated and their feedback on the process (e.g. Allen, et al. 2015; Baur \& Abma 2012; Boerema, van Velsen, Vollenbroek-Hutten, \& Hermens, 2017; Buckley, McCormack \& Ryan 2018; Doyle \& Timonen, 2010). Bulsara, Khong, Hill \& Hill (2016) is a notable exception to this and used a world café approach to facilitate input in an informal environment and through doing so not only derived useful information to inform future interventions but participants reported an increase in knowledge and awareness alongside enjoyment of the process. Similarly, our project team was small enough and consistent enough, that over a relatively short time, participants felt comfortable contributing to the discussions and we were able to have some healthy debate. In comparison with other published studies, we were transparent about our processes and largely were explicit about, and met our aims.

The identification of difficulties and suggestions for solutions came from our group discussions and were in line with behaviour change theory. In retrospect, having mapped barriers to the domains of 
DEarEST co-creation paper Health and Social Care in the Community

the TDF we were able to identify possible behaviour change techniques likeliest to be effective. For example, information addresses deficits in knowledge, encouragement, support and persuasive communication addresses a lack of confidence, context specific changes can address environmental barriers and devising prompts or making plans ahead of time addresses memory problems and the need for more thinking time (Abraham \& Michie, 2008; Michie, van Stralen, West, 2011). Our findings suggest that working with older people employing a co-creation model is a powerful way to create innovative and inclusive ideas and solutions. This is supported by two recent studies undertaken by 'Co:Create' addressing loneliness in older people in Sheffield and in Rotherham (Co:Create 2020). It is interesting that projects employing a co-creation approach are often not published in the academic literature but published on organisation websites, for example 'Co:Create's website. While this is useful as the information is more widely disseminated, it is arguable that providing insight into co-creation projects and process in the academic literature might be a useful adjunct, we have aimed to address this gap in this paper.

We are aware that our recommendations suggest a similar approach to addressing the issue of loneliness and isolation to that which has been successfully implemented in Frome, Somerset (Millington-Sanders, 2017). The Frome initiative is part of the work carried out by Compassionate Communities (Compassionate Communities UK, 2020) which aims to build on community resources to create community networks and support wellbeing in those who are facing the challenges of chronic ill health or ageing, including loneliness and isolation. The Frome model aims to 'reconnect people to both their own supportive network and the extensive community activity that already exists'. Their findings suggest a $30 \%$ reduction in emergency hospital admissions in three years. Our process led us to a similar model with the addition of the inclusion of the large volunteer resource available in this locality. This highlights the need for such models to be tailored to draw on individual neighbourhood and community resources, there cannot be a one size fits all intervention. Co- 
DEarEST co-creation paper Health and Social Care in the Community

creation allows the local knowledge, resources and understanding to shape an appropriate approach for each particular place.

There are undoubtedly overlaps with our proposed approach and the social prescribing model (Bickerdike, Booth, Wilson, Farley \& Wright, 2017), there are, however, also significant differences. A key part of the DEarEST model is the co-creation element, i.e. the central involvement of older people in the design and implementation; and the idea of drawing on resources that already exist within communities, for example volunteers. So while this project may be allied to, or have overlaps with social prescribing, the ways in which it differs are fundamental.

Rather than creating new services our recommendation for practice is to refine existing interventions and use local resources including residents, transport links and volunteers to promote access. Listening to, and working with, the local population is of vital importance when designing interventions to support healthy ageing and wellbeing as only they know what is required and the barriers to achievement.

Co-creation was a productive approach. There is, however, a need to be realistic about the scope of such a project, and to use diverse methods of recruitment and skilled facilitators, and to prepare well in terms of accessibility, simple systems, appropriate information provision. Research evidence offers guidance to conducting co-design but little of it is older people specific and even less is health promotion focused. There is a need to understand how we can galvanise the wisdom of our ageing population to develop sustainable, local initiatives to support healthy ageing.

There were a number of strengths and limitations to this study. Setting the study within a limited geographical area was both a strength and a limitation. This allowed the development of a context specific solution to local issues. The approach we used may not work in every situation. The funding 
DEarEST co-creation paper Health and Social Care in the Community

secured for this study allowed us to reach the point of preliminary intervention design which is yet to be tested. Despite our broad inclusion and recruitment strategy we did not engage with all sectors of the older population. The university members were successful in taking a step back and limiting their natural inclination to take a lead role however, in our assessment against the core values we have recognised areas for refinement in co-creation. There is no prescribed number for participation in a study such as this. Our evidence that this was enough is that we had full and wideranging discussion and all group members had the opportunity to take part.

In conclusion, the project team of lay older people and university members developed an understanding of the meaning of health and wellbeing in older age. We identified that loneliness and isolation are the keystone to all other elements of DEarEST. The most influential barriers to DEarEST were cognitive, lack of knowledge, lack of confidence and lack of access to adequate transport. What has been key to the development of our co-design work is that the findings and recommendations are "owned" by this group of older people in locality. The recommendations of the team are to create a "bridge" whereby individual need and existing resource are matched.

\section{Acknowledgements}

We would like to acknowledge the work carried out on this project by the lay members of the project group. 


\section{References}

Abraham, C. \& Michie, S. (2008). A taxonomy of behavior change techniques used in interventions. Health Psychology, 27, 379-387. doi: https://psycnet.apa.org/doi/10.1037/0278-6133.27.3.379

Allen, R. S., Azuero, C. B., Csikai, E. L., Parmelee, P. A., Shin, H. J., Kvale, E., Durkin, D. W. \& Burgio, L. D. (2015). "It was very rewarding for me": Senior volunteers' experiences with implementing a reminiscence and creative activity intervention. The Gerontologist, 56, 357-367. doi:

https://doi.org/10.1093/geront/gnu167

Baker, R., Camosso-Stefinovic, J., Gillies, C., Shaw, E. J., Cheater, F., Flottorp, S., Robertson, N., Wensing, M., Fiander, M., Eccles, M. P., Godycki-Cwirko, M., van Lieshout. \& Jäger, C. (2015). Tailored interventions to address determinants of practice. Cochrane Database of Systematic Reviews. 4. doi: https://doi.org/10.1002/14651858.CD005470.pub3

Banerjee, S. (2015). Multimorbidity-older adults need health care that can count past one. The Lancet, 385, 587-589. doi: https://doi.org/10.1016/S0140-6736(14)61596-8

Baur, V., \& Abma, T. (2012). 'The Taste Buddies': participation and empowerment in a residential home for older people. Ageing \& Society, 32, 1055-1078. doi

https://doi.org/10.1017/S0144686X11000766

Beard, H. P. J. R. \& Bloom, D. E. (2015). Towards a comprehensive public health response to population ageing. Lancet (London, England), 385, 658-661. doi:

https://dx.doi.org/10.1016\%2FS0140-6736(14)61461-6

Bickerdike, L., Booth, A., Wilson, P.M., Farley, K., \& Wright, K. (2017). Social prescribing: less rhetoric and more reality. A systematic review of the evidence, BMJ Open 7:e013384. doi:

http://dx.doi.org/10.1136/bmiopen-2016-013384

Blair, T. \& Minkler, M. (2009). Participatory action research with older adults: Key principles in practice. The Gerontologist, 49(5), 651-662. doi: https://doi.org/10.1093/geront/gnp049

Boerema, S. T., van Velsen, L., Vollenbroek-Hutten, M. M. \& Hermens, H. J. (2017). Value-based design for the elderly: An application in the field of mobility aids. Assistive technology, 29(2), 76-84. doi https://doi.org/10.1080/10400435.2016.1208303

Botero, A., \& Hyysalo, S. (2013). Ageing together: Steps towards evolutionary co-design in everyday practices. CoDesign: International Journal of CoCreation in Design and the Arts, 9, 37-54. doi: https://doi.org/10.1080/15710882.2012.760608

Bruggencate, T., Luijkx, K., \& Sturm, J. (2018). Social needs of older people: a systematic literature review. Ageing \& Society, 38, 1745-1770. doi: https://doi.org/10.1017/S0144686X17000150

Buckley, C., McCormack, B. \& Ryan, A. (2018). Working in a storied way: Narrative-based approaches to person-centred care and practice development in older adult residential care settings. Journal of Clinical Nursing, 27, e858-e872. https://doi.org/10.1111/jocn.14201 
Bulsara, C., Khong, L., Hill, K. \& Hill, A. M. (2016). Investigating community perspectives on falls prevention information seeking and delivery: older person perceptions regarding preferences for falls prevention education using a world cafe approach. Journal of Community Psychology, 44, 937944. doi: https://doi.org/10.1002/icop.21816

Cameron, I., Gillespie, L., Robertson, C., Murray, G., Hill, K., Cumming, R. \& Kerse, N. (2012). Interventions for preventing falls in older people in care facilities and hospitals. Cochrane Database of Systematic Reviews, 12. doi https://doi.org/10.1002/14651858.CD005465.pub4

Co-create. (2020). Core values. Retreived from https://www.wearecocreate.com/about

Compassionate Communities UK. (2020). Our mission. Retreived from https://www.compassionatecommunitiesuk.co.uk/what-we-do

Craig, P., Dieppe, P., Macintyre, S., Michie, S., Nazareth, I. \& Petticrew, M. (2008). Developing and evaluating complex interventions: the new Medical Research Council guidance. BMJ, 337, a1655. doi: https://doi.org/10.1136/bmi.a1655

Domènech-Abella, J., Lara, E., Rubio-Valera, M., Olaya, B., Moneta, M.V., Rico-Uribe, L.A., AyusoMateos, J.L., Mundó, J., \& Haro, J.M. (2017). Loneliness and depression in the elderly: the role of social network. Social Psychiatry and Psychiatric Epidemiology, 52, 381-90. doi:

https://doi.org/10.1007/s00127-017-1339-3

Doyle, M. \& Timonen, V. (2010). Lessons from a community-based participatory research project: Older people's and researchers' reflections. Research on Aging, 32, 244-263. doi:

https://doi.org/10.1177\%2F0164027509351477

Filipe, A., Renedo, A. \& Marston, C. (2017). The co-production of what? Knowledge, values, and social relations in health care. PLoS Biology, 15, e2001403. doi:

https://dx.doi.org/10.1371\%2Fiournal.pbio.2001403

Flinders, M., Wood, M. \& Cunningham, M. (2016). The politics of co-production: risks, limits and pollution. Evidence \& Policy: A Journal of Research, Debate and Practice, 12, 261-279. doi: https://doi.org/10.1332/174426415X14412037949967

Frost, R., Belk, C., Jovicic, A., Ricciardi, F., Kharicha, K., Gardner, B., Iliffe, S., Goodman, C., Manthorpe, J. \& Drennan, V. M. (2017). Health promotion interventions for community-dwelling older people with mild or pre-frailty: a systematic review and meta-analysis. BMC Geriatrics, 17(1), 157. doi: https://doi.org/10.1186/s12877-017-0547-8

Gardiner, C., Geldenhuys, G. \& Gott, M. (2018). Interventions to reduce social isolation and loneliness among older people: an integrative review. Health \& Social Care in the Community, 26, 147-157. doi: https://doi.org/10.1111/hsc.12367

Gardner, B., Jovicic, A., Belk, C., Kharicha, K., lliffe, S., Manthorpe, J., Goodman, C., Drennan, V. M. \& Walters, K. (2017). Specifying the content of home-based health behaviour change interventions for older people with frailty or at risk of frailty: an exploratory systematic review. BMJ Open, 7, e014127. doi: http://dx.doi.org/10.1136/bmjopen-2016-014127

Gulia, K. K., \& Kumar, V.M. (2018). Sleep disorders in the elderly: a growing challenge.

Psychogeriatrics. 18, 155-65. doi: https://doi.org/10.1111/psyg.12319 
Grönvall, E. \& Kyng, M. (2013). On participatory design of home-based healthcare. Cognition, Technology \& Work, 15, 389-401. doi: https://doi.org/10.1007/s10111-012-0226-7

Högberg, B., Strandh, M., Baranowska-Rataj, A. \& Sevä, I. J. (2017). Ageing, health inequalities and the welfare state: A multilevel analysis. Journal of European Social Policy, 28, 311-325. doi: https://doi.org/10.1177\%2F0958928717739234

Holt-Lunstad, J., Smith, T. B. \& Layton, J. B. (2010). Social relationships and mortality risk: a metaanalytic review. PLoS Medicine, 7, e1000316. doi: https://doi.org/10.1371/iournal.pmed.1000316

Jankovic, N., Geelen, A., Streppel, M.T., De Groot, L.C., Orfanos, P., Van Den Hooven, E.H., Pikhart, H., Boffetta, P., Trichopoulou, A., Bobak, M., \& Bueno-de-Mesquita, H.B. (2014). Adherence to a healthy diet according to the World Health Organization guidelines and all-cause mortality in elderly adults from Europe and the United States. American Journal of Epidemiology, 180, 978-88. doi: https://doi.org/10.1093/aje/kwu229

Jansen, S., \& Pieters, M. (2017). The 7 principles of complete co-creation. Amsterdam: Bis Publishers.

Leong T.W., \& Johnston B. (2016). Co-design and Robots: A Case Study of a Robot Dog for Aging People. In: Agah A., Cabibihan JJ., Howard A., Salichs M., He H. (eds) Social Robotics. ICSR 2016. Lecture Notes in Computer Science, 9979. Springer, Cham. doi: https://doi.org/10.1007/978-3-319$\underline{47437-3 \quad 69}$

Jackson, C. L. \& Greenhalgh, T. (2015). Co-creation: a new approach to optimising research impact. Medical Journal of Australia, 203, 283-4. doi: 10.5694/mja15.00219

Liljas, A. E., Walters, K., Jovicic, A., lliffe, S., Manthorpe, J., Goodman, C. \& Kharicha, K. (2017). Strategies to improve engagement of 'hard to reach'older people in research on health promotion: a systematic review. BMC Public Health, 17, 349. doi: https://doi.org/10.1186/s12889-017-4241-8

Littlechild, R., Tanner, D. \& Hall, K. (2015). Co-research with older people: perspectives on impact. Qualitative Social Work, 14, 18-35. doi: https://doi.org/10.1177\%2F1473325014556791

Lood, Q., Häggblom-Kronlöf, G. \& Dahlin-Ivanoff, S. (2015). Health promotion programme design and efficacy in relation to ageing persons with culturally and linguistically diverse backgrounds: a systematic literature review and meta-analysis. BMC Health Services Research, 15, 560. doi: https://doi.org/10.1186/s12913-015-1222-4

Martino, J., Pegg, J., \& Frates, E.P. (2015). The connection prescription: Using the power of social interactions and the deep desire for connectedness to empower health and wellness. American Journal of Lifestyle Medicine, 11, 466-475. doi: https://doi.org/10.1177\%2F1559827615608788

McEachan, R. R., Santorelli, G., Bryant, M., Sahota, P., Farrar, D., Small, N., Akhtar, S., Sargent, J., Barber, S. E. \& Taylor, N. (2016). The HAPPY (Healthy and Active Parenting Programmme for early Years) feasibility randomised control trial: acceptability and feasibility of an intervention to reduce infant obesity. BMC Public Health, 16, 211. doi: https://doi.org/10.1186/s12889-016-2861-z

Michie, S., Johnston, M., Abraham, C., Lawton, R., Parker, D. \& Walker, A. (2005). Making psychological theory useful for implementing evidence based practice: a consensus approach. $B M J$ Quality \& Safety, 14(1), 26-33. doi: 10.1136/qshc.2004.011155 
Michie, S., Van Stralen, M. M. \& West, R. (2011). The behaviour change wheel: a new method for characterising and designing behaviour change interventions. Implementation Science, 6(1), 42. doi: https://doi.org/10.1186/1748-5908-6-42

Millington-Sanders, C. (2017). Compassionate Communities: using robust methodology to rocket boost results for people living and working in UK. Retrieved from https://www.kingsfund.org.uk/sites/default/files/2017-11/Catherine\%20Millington\%20Sanders.pdf

Ministry of Housing, Communities \& Local Government. (2019). The English Indices of Deprivation. Retrieved from

https://assets.publishing.service.gov.uk/government/uploads/system/uploads/attachment data/file /835115/loD2019 Statistical Release.pdf).

Morgan, T., Wiles, J., Park, H-J., Moeke-Maxwell, T., Dewes, O., Black, S., Williams, L., Gott, M. (2019). Social connectedness: what matters to older people? Ageing \& Society 1-19. doi: https://doi.org/10.1017/S0144686X1900165X

Munir, F., Biddle, S. J., Davies, M. J., Dunstan, D., Esliger, D., Gray, L. J., Jackson, B. R., O'Connell, S. E., Yates, T. \& Edwardson, C. L. (2018). Stand More AT Work (SMArT Work): using the behaviour change wheel to develop an intervention to reduce sitting time in the workplace. BMC Public Health, 18, 319. doi: https://doi.org/10.1186/s12889-018-5187-1

National Institute for Health Research INVOLVE (2020). Co production. Retreived from https://www.invo.org.uk/current-work/co-production/

Newall, N. E. \& Menec, V. H. (2015). Targeting socially isolated older adults: a process evaluation of the senior centre without walls social and educational program. Journal of Applied Gerontology, 34, 958-976. doi: https://doi.org/10.1177\%2F0733464813510063

Oliveira, J. S., Sherrington, C., Amorim, A. B., Dario, A. B. \& Tiedemann, A. (2017). What is the effect of health coaching on physical activity participation in people aged 60 years and over? A systematic review of randomised controlled trials. British Journal of Sports Medicine, 51, 1425-1432. doi: http:// dx. doi. org/ 10. 1136/ bjsports- 2016- 096943

Olofsson, J., Padyab, M. \& Malmberg, G. (2018). Health disparities in Europe's ageing population: the role of social network. Global Health Action, 11, 1445498. doi:

https://doi.org/10.1080/16549716.2018.1445498

O'Rourke, H.M., Collins, L., \& Sidani, S. (2018). Interventions to address social connectedness and loneliness for older adults: a scoping review. BMC Geriatrics, 18, 214. doi:

https://doi.org/10.1186/s12877-018-0897-x

Palinkas, L.A., Horwitz, S.M., Green, C.A., Wisdom, P., Duan, N., \& Hoagwood, K. (2015). Purposeful Sampling for Qualitative Data Collection and Analysis in Mixed Method Implementation Research. Administration and Policy in Mental Health and Mental Health Research. 42, 533-544. doi: https://doi.org/10.1007/s10488-013-0528-y

Patnode, C. D., Evans, C. V., Senger, C. A., Redmond, N. \& Lin, J. S. (2017). Behavioral counseling to promote a healthful diet and physical activity for cardiovascular disease prevention in adults without known cardiovascular disease risk factors: updated evidence report and systematic review for the US Preventive Services Task Force. JAMA, 318, 175-193. doi:10.1001/jama.2017.3303 
DEarEST co-creation paper Health and Social Care in the Community

Picetti, D., Foster, S, Pangle, A.K., Schrader, A., George, M., Wei, J.Y. \& Azhar, G. (2017). Hydration health literacy in the elderly. Nutrition and Healthy Ageing, 4, 227-37.doi: 10.3233/NHA-170026

Ryan, G.W. \& Bernard, H.R. (2003) Techniques to identify themes. Field Notes, 15, 85-109. https://doi.org/10.1177\%2F1525822X02239569

Schilling, I., \& Gerhardus, A. (2017). Methods for involving older people in health research-a review of the literature. International Journal of Environmental Research and Public Health, 14, 1476. doi: https://doi.org/10.3390/ijerph14121476

Shankar, A., McMunn, A., Banks, J. \& Steptoe, A. (2011), Loneliness, social isolation, and behavioral and biological health indicators in older adults. Health Psychology, 30, 377-385. doi: https://psycnet.apa.org/doi/10.1037/a0022826

Shimmin, C., Wittmeier, K. D., Lavoie, J. G., Wicklund, E. D. \& Sibley, K. M. (2017). Moving towards a more inclusive patient and public involvement in health research paradigm: the incorporation of a trauma-informed intersectional analysis. BMC Health Services Research, 17, 539. Doi: https://doi.org/10.1186/s12913-017-2463-1

Stebbins, R. A. (2001). Exploratory research in the social sciences. Thousand Oaks: Sage.

Steptoe, A., Deaton, A. \& Stone, A. A. (2015). Subjective wellbeing, health, and ageing. The Lancet, 385, 640-648. doi: https://doi.org/10.1016/S0140-6736(13)61489-0

Suzman, R., Beard, J. R., Boerma, T. \& Chatterji, S. (2015). Health in an ageing world - what do we know? The Lancet, 385, 484-486. doi: https://doi.org/10.1016/S0140-6736(14)61597-X

Taylor, D. (2014).Physical activity is medicine for older adults. Postgraduate Medical Journal. 90, 2632. http://dx.doi.org/10.1136/postgradmedj-2012-131366

Taylor, N. J., Sahota, P., Sargent, J., Barber, S., Loach, J., Louch, G. \& Wright, J. (2013). Using intervention mapping to develop a culturally appropriate intervention to prevent childhood obesity: the HAPPY (Healthy and Active Parenting Programme for Early Years) study. International Journal of Behavioral Nutrition and Physical Activity, 10, 142. doi: https://doi.org/10.1186/1479-5868-10-142

Taylor, H. O., Taylor, R. J., Nguyen, A. W. \& Chatters, L. (2018). Social isolation, depression, and psychological distress among older adults. Journal of Aging and Health, 30, 229-246. doi: https://doi.org/10.1177\%2F0898264316673511

UK Research and Innovation (2020). Healthy Ageing. Retreived from https://www.ukri.org/innovation/industrial-strategy-challenge-fund/healthyageing/\#pagecontentid-0

World Health Organisation (2020). 10 Priorities for a decade of Action on Healthy Ageing. Retreived from https://www. who.int/ageing/10-priorities/en/ 